\title{
AVALIAÇÃO DE CULTIVARES DE SORGO GRANÍFERO NA SAFRINHA EM JATAÍ, GO
}

\author{
José Hortêncio Mota ${ }^{1}$, Lazaro Kleber Assis Bevilaqua ${ }^{1}$, Cicero Bezerra de Menezes ${ }^{2}$
}

\footnotetext{
${ }^{1}$ Universidade Federal de Goiás, Regional Jataí, E-mail: hortenciomota@terra.com.br ${ }^{1}$, kleberbevilaqua@ hotmail.com $^{1}$

${ }^{2}$ EMBRAPA Milho e Sorgo, E-mail: cicero.menezes@embrapa.br ${ }^{2}$
}

\section{RESUMO}

Este trabalho teve como objetivo avaliar o desempenho agronômico de 24 híbridos de sorgo granífero, no período de safrinha (março a junho), nas condições edafoclimáticas de Jataí, Estado de Goiás. Verificou-se que os híbridos 1096030, 10102063, 729033 e 1105653 foram os mais produtivos, com produção acima da média regional, sendo que o híbrido 1096030 destacou-se pelo maior comprimento de panícula, maior altura de planta, maior produção de massa fresca e maior rendimento de grãos, apresentando, portanto, potencial para uso em silagens.

Palavras-chave: Sorghum bicolor, Avaliação de cultivares, Produtividade

\section{EVALUATION OF GRAIN SORGHUM CULTIVARS FOR DOUBLE CROPPING IN JATAÍ, STATE OF GOIÁS, BRAZIL}

\section{ABSTRACT}

This paper evaluates the agronomic performance of 24 hybrids of sorghum in the period from March to June (second season), in the weather conditions of Jataí, State of Goiás, Brazil. The hybrids 1096030, 10102063, 1105653 and 729033 were the most productive ones with production above the regional average, while the hybrid 1096030 stood out due to its higher panicle length, higher plant height, higher fresh mass and higher grain yield, and thus a potential for use in silage.

Keywords: Sorghum bicolor, Cultivar evaluation, Productivity

\section{INTRODUÇÃO}

Atualmente, o sorgo é considerado o quinto cereal mais produzido no mundo, depois do milho, trigo, arroz e cevada, com uma produção mundial em 2011 de 62,3 milhões de toneladas, em uma área de 42,2 milhões de hectares (FAO, 2014).
A estimativa da área plantada de sorgo na safrinha 2014/2015 no Brasil foi de 721,0 mil hectares, com rendimento médio de produção de 2,71 toneladas $\mathrm{ha}^{-1}$, apresentando aumento de 4,6\% em relação à safra anterior. O Estado de Goiás lidera a produção nacional com 851,5 mil toneladas, 
apresentando um acréscimo de 20,3\% em relação à safra anterior. Minas Gerais vem em segundo lugar com 499,7 mil toneladas, seguido por Mato Grosso (291,5 mil toneladas) (CONAB, 2015).

Com a elevação do preço das sementes de milho, em função da incorporação dos eventos transgênicos, e com o avanço dos programas de melhoramento de sorgo para aumento de produtividade, a cultura do sorgo tornou-se de grande interesse para o produtor como uma segunda fonte de renda (safrinha), permitindo a utilização da mesma estrutura de cultivo (maquinário) empregada para o cultivo da soja e do milho.

Segundo Véras (2005), o milho é a principal fonte de energia utilizada no Brasil para compor os concentrados, porém sofre grande variação de preço ao longo do ano, haja vista sua intensa utilização na alimentação humana e na dieta de aves e suínos. Em decorrência disso, vários trabalhos têm sido desenvolvidos no intuito de encontrar fontes de energia alternativas ao milho na dieta de ruminantes.

Uma das grandes vantagens da cultura do sorgo é sua adaptação a diversos ambientes, por apresentar maior tolerância à deficiência hídrica e solos com baixa fertilidade, em comparação com outras culturas de grãos, especialmente o milho. Seu cultivo tem sido muito utilizado na safrinha, onde o desempenho tem sido melhor que o da cultura do milho (VON PINHO et al., 2007), o que possibilita sua expansão em regiões com distribuição irregular de chuvas, e até verão (RODRIGUES FILHO et al., 2006).

A cultura do sorgo granífero apresenta amplo potencial para uso nos cultivos de safrinha na região Centro-Oeste onde é possível mecanizar todas as práticas culturais da lavoura. Adicionalmente, essa cultura permite, ainda, maior amplitude da época de semeadura, possibilitando maior flexibilidade na implantação da cultura (PALE et al., 2003), ou seja, lavouras de milho semeadas após o dia 20 de fevereiro tendem a apresentar grande sensibilidade ao estresse hídrico, durante seu desenvolvimento e a cultura do sorgo vem como uma alternativa para plantios após a referida data.

A semeadura de cultivares de sorgo adaptadas aos sistemas de produção e às condições ambientais da região de cultivo, além do manejo adequado da cultura, constitui fator importante para a maximização da produção de massa verde, matéria seca e grãos utilizados na alimentação animal (SANTOS \& GRANGEIRO, 2013). Devido ao grande aumento da demanda do sorgo no Brasil, faz-se necessária a busca de novas 
cultivares produtivas e adaptadas para as mais diversas regiões do país.

Dentre as principais características agronômicas desejáveis para a escolha de uma cultivar, destacam-se o rendimento de grãos e o rendimento de massa verde e sua composição química, os quais são marcadamente afetados pelas condições ecológicas da região de plantio.

Neste contexto, objetivou-se avaliar características de importância agronômica de 24 híbridos de sorgo granífero, no período de safrinha, nas condições edafoclimáticas de Jataí, região sudoeste do Estado de Goiás.

\section{MATERIAL E MÉTODOS}

O experimento foi conduzido na safrinha de 2013, em área experimental na Regional Jataí da Universidade Federal de Goiás (UFG), localizada nas coordenadas $17^{\circ} 53^{\prime} \mathrm{S}$ e $51^{\circ} 43^{\prime} \mathrm{O}$, a uma altitude média de 670 m. O clima da região, segundo a classificação de Köppen, é do tipo Aw tropical de savana e megatérmico com estações seca e chuvosa definidas. A precipitação varia de $1.650 \mathrm{~mm}$ a $1.800 \mathrm{~mm}$ e a temperatura média anual é de $22^{\circ} \mathrm{C}$.

O solo da área experimental é classificado como Latossolo Vermelho distroférrico. A amostragem do solo foi realizada na camada de 0 a $20 \mathrm{~cm}$ e as características químicas do solo utilizado foram: $\mathrm{pH}=5,83 \mathrm{em} \mathrm{CaCl}_{2} ; \mathrm{P}=10,7 \mathrm{mg}$ $\mathrm{dm}^{-3} ; \mathrm{K}=64 \mathrm{mg} \mathrm{dm}{ }^{-3} ; \mathrm{Ca}^{2+}=3,52$ Cmolc $\mathrm{dm}^{-3} ; \mathrm{Mg}^{2+}=1,21$ Cmolc $\mathrm{dm}^{-3} ; \mathrm{Al}^{3+}=0,1$ Cmolc dm ${ }^{-3} ; \mathrm{H}+\mathrm{Al}=9,56$ Cmolc $\mathrm{dm}^{-3}$.

A área onde foi conduzido o experimento foi ocupada nos últimos anos pela sucessão soja/sorgo no sistema de plantio direto. $\mathrm{O}$ delineamento experimental utilizado foi o de blocos casualizados, com três repetições. A semeadura foi realizada manualmente no início do mês de março, sendo as parcelas compostas por quatro linhas de $5 \mathrm{~m}$ de comprimento, com espaçamento de 0,45 m entre linhas, e apenas as duas fileiras centrais foram consideradas como área útil de avaliação e coleta de dados.

Foram avaliados 24 híbridos de sorgo granífero, semeados manualmente, sendo 21 desenvolvidos pelo programa de melhoramento genético da Embrapa Milho e Sorgo (0729033, 0843009, 1096012, 1096019, 1096030, 1099020, 1099034, 1099038, 1099044, 1105653, 1167010, 1167026, 1167048, 1167093, 1168092, 1168093, 1169026, 1169054, 1169056, 1170026 e 10102063) e três híbridos comerciais (BRS 304, BRS 330 e DKB 551). A adubação de plantio consistiu da aplicação de $450 \mathrm{~kg} \mathrm{ha}^{-1}$ da formulação NPK 04-20-18 e para adubação de cobertura $200 \mathrm{~kg} \mathrm{ha}^{-1}$ de ureia, 30 dias após a semeadura. 
As parcelas foram mantidas livres de invasoras, realizando-se capina manual. A colheita foi realizada manualmente aos 120 dias após o plantio, coletando-se as panículas presentes na área útil das parcelas. As características avaliadas foram: dias entre a semeadura e o emborrachamento (emissão de panículas, em $50 \%$ das plantas); dias entre a semeadura e o florescimento (número de dias da semeadura até o período em que a porção mediana da panícula apresentasse as flores abertas, em 50\% das plantas); altura de plantas (distância entre o colo da planta e o ápice da panícula); comprimento da panícula; massa seca acumulada (por meio da determinação da massa seca em câmara de circulação forçada de ar a $70^{\circ} \mathrm{C}$ ); produção de massa fresca de plantas e rendimento de grãos (pesagem dos grãos, corrigindo-se a umidade para $13 \%$ ).

Os dados obtidos foram submetidos à análise de variância, sendo as médias comparadas pelo teste de Scott-Knott a 5\% de probabilidade. As análises foram feitas com auxílio do programa computacional SISVAR 5.1 (FERREIRA, 2011).

\section{RESULTADOS E DISCUSSÃO}

A análise de variância revelou diferença significativa para as características florescimento (dias), comprimento de panículas (cm), altura de plantas (m), umidade de plantas (\%), produção de massa fresca de plantas $\left(\mathrm{t} \mathrm{ha} \mathrm{h}^{-1}\right)$ e rendimento de grãos $\left(\mathrm{t} \mathrm{ha}^{-1}\right)$. Apenas a característica número de dias até o emborrachamento não apresentou diferença estatística para os híbridos avaliados (Tabela 1).

Os genótipos avaliados apresentaram início da fase de emborrachamento em torno dos 54 dias após o plantio. É importante enfatizar que culturas destinadas à safrinha ou semeadas em regiões de clima semiárido não devem ter ciclo longo, minimizando assim os riscos decorrentes de um possível estresse hídrico (ALMEIDA FILHO et al., 2010).

Quanto mais antecipado for o emborrachamento, mais precoce será o florescimento, o que é desejável onde se planeja fazer silagem do material vegetal.

Em relação à época de florescimento das plantas de sorgo, verificou-se que os híbridos 10102063, 1096019 e 1169054 apresentaram florescimento precoce (55 a 58 dias após semeadura) enquanto o híbrido 1099038 apresentou o florescimento mais tardiamente (72 dias após o plantio), sendo que o florescimento médio situou-se em torno de 62 dias. Resultados semelhantes para florescimento foram obtidos por Heckler (2002) que, avaliando 18 genótipos de sorgo, observou que a maioria dos materiais apresentou florescimento médio em torno de 
62 dias. Observa-se, assim, que o período do florescimento dos materiais avaliados fornece ao agricultor informações para o planejamento de cultivo, pois materiais mais precoces permitem a liberação da área de cultivo mais rapidamente.

Tabela 1. Valores médios do número de dias até o emborrachamento (Emb.) e até o florescimento (Flor.), comprimento de panículas (Pan.), altura de plantas (H), massa seca acumulada (MS), produção de massa fresca (MF) e rendimento de grãos (Rend.), de híbridos de sorgo cultivado na safrinha em Jataí, GO, 2013.

\begin{tabular}{|c|c|c|c|c|c|c|c|}
\hline Híbrido & $\begin{array}{l}\text { Emb. } \\
\text { (dias) }\end{array}$ & $\begin{array}{l}\text { Flor. } \\
\text { (dias) }\end{array}$ & $\begin{array}{l}\text { Pan. } \\
(\mathrm{cm})\end{array}$ & $\begin{array}{c}\mathbf{H} \\
(\mathbf{m})\end{array}$ & $\begin{array}{l}\text { MS } \\
(\%)\end{array}$ & $\begin{array}{c}\text { MF } \\
\left(t^{h} \mathbf{h}^{-1}\right)\end{array}$ & $\begin{array}{l}\text { Rend. } \\
\left(t^{\text {ha-1 }}\right)\end{array}$ \\
\hline 1096030 & $53 \mathrm{a}$ & $64 \mathrm{~b}$ & $52,0 \mathrm{a}$ & $1,76 \mathrm{a}$ & $37,1 \mathrm{c}$ & $36,26 \mathrm{a}$ & $4,09 \mathrm{a}$ \\
\hline 10102063 & $49 \mathrm{a}$ & $58 \mathrm{~d}$ & $49,0 \mathrm{a}$ & $1,86 \mathrm{a}$ & $31,7 \mathrm{c}$ & $41,11 \mathrm{a}$ & $3,91 \mathrm{a}$ \\
\hline 729033 & $54 \mathrm{a}$ & $64 \mathrm{~b}$ & $39,3 \mathrm{~b}$ & $1,47 \mathrm{~b}$ & $49,9 \mathrm{~b}$ & $25,44 b$ & $3,76 \mathrm{a}$ \\
\hline 1105653 & $56 a$ & $61 \mathrm{c}$ & $38,7 \mathrm{~b}$ & $1,36 \mathrm{c}$ & $37,1 \mathrm{c}$ & $24,81 \mathrm{~b}$ & $3,62 \mathrm{a}$ \\
\hline 1167026 & $54 \mathrm{a}$ & $67 \mathrm{~b}$ & $43,3 \mathrm{a}$ & $1,40 \mathrm{~b}$ & $34,1 \mathrm{c}$ & $24,11 b$ & $3,40 \mathrm{~b}$ \\
\hline 1169026 & $57 \mathrm{a}$ & $65 \mathrm{~b}$ & $41,0 \mathrm{~b}$ & $1,35 \mathrm{c}$ & $33,9 \mathrm{c}$ & $32,52 \mathrm{a}$ & $3,39 \mathrm{~b}$ \\
\hline 1099020 & $53 \mathrm{a}$ & $60 c$ & $49,3 \mathrm{a}$ & $1,83 \mathrm{a}$ & $38,8 \mathrm{c}$ & $26,70 \mathrm{~b}$ & $3,14 \mathrm{~b}$ \\
\hline DKB 551 & $53 \mathrm{a}$ & $63 \mathrm{~b}$ & $35,0 \mathrm{c}$ & $1,17 \mathrm{~d}$ & $32,5 \mathrm{c}$ & $35,11 \mathrm{a}$ & $3,13 \mathrm{~b}$ \\
\hline 1099034 & $56 a$ & $66 \mathrm{~b}$ & $40,0 \mathrm{~b}$ & $1,28 \mathrm{c}$ & $48,7 \mathrm{~b}$ & $16,67 \mathrm{c}$ & $3,00 \mathrm{c}$ \\
\hline BRS 330 & $54 \mathrm{a}$ & $65 \mathrm{~b}$ & $45,3 \mathrm{a}$ & $1,39 \mathrm{~b}$ & $50,1 \mathrm{~b}$ & $20,07 \mathrm{c}$ & $2,95 \mathrm{c}$ \\
\hline 1167048 & $51 \mathrm{a}$ & $59 c$ & $45,3 \mathrm{a}$ & $1,32 \mathrm{c}$ & $44,0 \mathrm{c}$ & $16,67 \mathrm{c}$ & $2,95 \mathrm{c}$ \\
\hline 1170026 & $57 \mathrm{a}$ & $66 \mathrm{~b}$ & $32,7 \mathrm{c}$ & $1,50 \mathrm{~b}$ & $33,9 \mathrm{c}$ & $26,04 \mathrm{~b}$ & $2,94 \mathrm{c}$ \\
\hline 1167010 & $55 \mathrm{a}$ & $65 \mathrm{~b}$ & $40,7 \mathrm{~b}$ & $1,36 \mathrm{c}$ & $46,3 \mathrm{c}$ & $15,89 \mathrm{c}$ & $2,74 \mathrm{c}$ \\
\hline 1169056 & $52 \mathrm{a}$ & $60 c$ & $47,7 \mathrm{a}$ & $1,39 \mathrm{~b}$ & $54,6 \mathrm{~b}$ & $14,17 \mathrm{c}$ & $2,69 \mathrm{c}$ \\
\hline 1099044 & $54 \mathrm{a}$ & $62 \mathrm{~b}$ & $41,3 \mathrm{~b}$ & $1,38 \mathrm{~b}$ & $52,3 \mathrm{~b}$ & $11,63 \mathrm{c}$ & $2,68 \mathrm{c}$ \\
\hline 1169054 & $53 \mathrm{a}$ & $55 \mathrm{~d}$ & $45,7 \mathrm{a}$ & $1,44 \mathrm{~b}$ & $42,6 \mathrm{c}$ & $17,89 \mathrm{c}$ & $2,65 \mathrm{c}$ \\
\hline 843009 & $54 \mathrm{a}$ & $61 \mathrm{c}$ & $44,7 \mathrm{a}$ & $1,25 \mathrm{c}$ & $54,7 \mathrm{~b}$ & $16,65 \mathrm{c}$ & $2,63 \mathrm{c}$ \\
\hline 1167093 & $54 \mathrm{a}$ & $65 \mathrm{~b}$ & $28,3 \mathrm{c}$ & $1,12 \mathrm{~d}$ & $71,4 \mathrm{a}$ & $14,96 \mathrm{c}$ & $2,43 \mathrm{~d}$ \\
\hline 1168092 & $53 a$ & $64 \mathrm{~b}$ & $44,3 \mathrm{a}$ & $1,32 \mathrm{c}$ & $53,2 \mathrm{~b}$ & $13,70 \mathrm{c}$ & $2,43 \mathrm{~d}$ \\
\hline 1168093 & $56 a$ & $65 \mathrm{~b}$ & $45,0 \mathrm{a}$ & $1,30 \mathrm{c}$ & $44,3 \mathrm{c}$ & $17,87 \mathrm{c}$ & $2,32 \mathrm{~d}$ \\
\hline 1096012 & $55 \mathrm{a}$ & $65 \mathrm{~b}$ & $43,7 \mathrm{a}$ & $1,23 \mathrm{~d}$ & $58,7 \mathrm{~b}$ & $15,81 \mathrm{c}$ & $2,27 \mathrm{~d}$ \\
\hline 1096019 & $52 \mathrm{a}$ & $56 \mathrm{~d}$ & $51,0 \mathrm{a}$ & $1,47 \mathrm{~b}$ & $44,0 \mathrm{c}$ & $13,22 \mathrm{c}$ & $2,26 \mathrm{~d}$ \\
\hline BRS 304 & $52 \mathrm{a}$ & $61 \mathrm{c}$ & $46,0 \mathrm{a}$ & $1,29 \mathrm{c}$ & $67,4 \mathrm{a}$ & $12,59 \mathrm{c}$ & $2,23 \mathrm{~d}$ \\
\hline 1099038 & $60 \mathrm{a}$ & $72 \mathrm{a}$ & $31,7 \mathrm{c}$ & $0,93 \mathrm{e}$ & $45,6 \mathrm{c}$ & $11,80 \mathrm{c}$ & $1,55 \mathrm{e}$ \\
\hline Média & 54 & 63 & 42,5 & 1,38 & 46,1 & 20,90 & 2,88 \\
\hline $\mathrm{CV} \%$ & 5,7 & 3,5 & 13,5 & 4,5 & 21,6 & 18,3 & 12,3 \\
\hline
\end{tabular}

Médias seguidas por mesma letra não diferem entre si pelo teste de $\operatorname{Scott} \operatorname{Knott}(\alpha=0,05)$. 
Houve variação no número de dias para o florescimento das plantas de sorgo, sendo que os mais precoces floresceram com 55 dias e os mais tardios com 72 dias, uma variação de $31 \%$ ou 17 dias,

De acordo com Tardin et al. (2012), é importante que existam cultivares com diferentes épocas de florescimento disponíveis para o agricultor, para que o mesmo possa diversificar os genótipos a serem semeados, optando preferencialmente por semear cultivares tardias no início da safra e mais precoces no final do período de semeadura, pois híbridos com ciclos diferentes favorecem a colheita escalonada.

Verificou-se que os híbridos que floresceram mais precocemente sofreram maiores danos causados por pássaros em relação aos demais. Devido ao fato de não apresentar proteção para sementes (empalhamento), a planta de sorgo produz vários compostos fenólicos (taninos) que servem como defesa química contra pássaros, patógenos e outros competidores (DINIZ, 2010). A presença do tanino no grão de sorgo depende da constituição genética do material, havendo controvérsias, uma vez que, apesar de algumas vantagens agronômicas, como resistência a pássaros e doenças do grão, quando o mesmo for utilizado na alimentação animal poderá causar distúrbios digestivos no animal diminuindo a sua palatabilidade e digestibilidade (RODRIGUEZ et al., 1999).

Em relação ao comprimento de panícula, os híbridos avaliados apresentaram comprimento médio $42,5 \mathrm{~cm}$, sendo que os híbridos BRS 304, BRS 330, 843009, 1096012, 1096019, 1096030, 1099020, 1167026, 1167048, 1168092, 1168093, 1169054, 1169056 e 10102063 foram os que apresentaram maiores panículas.

O comprimento de panícula é uma característica desejável, pois possibilita maior quantidade de grãos e, consequentemente, incremento de produtividade. De acordo com Avelino et al. (2011), a panícula, além de representar grande parte da matéria seca, contém grande valor nutricional devido a sua composição rica em carboidratos não estruturais.

De acordo com Silva et al. (2009), uma das características importantes na escolha de cultivares de sorgo granífero é o porte das plantas. Cultivares que apresentam menor altura de plantas, associada à maior resistência de colmo, apresentam menor suscetibilidade ao acamamento ou quebra das plantas. Avelino et al. (2011) relatam que fenótipos de porte alto têm grande potencial para produção de silagens, desde que apresentem valor nutritivo. 
Verificou-se que apenas o híbrido 1099038 apresentou altura de 1,0 m e os híbridos 1099020, 10102063 e 1096030 apresentaram altura superior a $1,5 \mathrm{~m}$. Recomenda-se que esses genótipos com porte superior a 1,5 m não sejam cultivados em locais com incidência de ventos fortes, pois há uma probabilidade de perdas devido ao acamamento.

A análise do percentual de umidade das plantas é importante quando se avalia o período para colheita da silagem, devendo os híbridos não apresentar teores muito elevados, ficando em torno de $30 \%$ a $35 \%$ de massa seca.

Para os 24 híbridos avaliados, a umidade média da planta no instante da colheita foi de $46,1 \%$, sendo que 14 híbridos (1168093, 1169026, DKB 551, 1169054, 1105653, 1170026, 1099038, 1099020, 1167026, 1167010, 10102063, 1167048, 1096030 e 1096019) apresentaram teor de umidade abaixo desse valor médio.

Em relação à massa fresca de plantas, verificou-se que os híbridos avaliados apresentaram média de produção de 20,90 $\mathrm{t} \mathrm{ha}^{-1}$, com destaque para os genótipos 1096030, 10102063, 1169026 e DKB 551 que apresentaram as maiores produções.

De acordo com Paziani \& Duarte (2006), as produtividades de sorgo variaram de 28,6 a 137,7 t ha $^{-1}$ de massa verde. Esta amplitude revela não só a variabilidade genética dos materiais avaliados, mas também a influência de fatores ambientais sobre a produtividade de sorgo para silagem.

Considerando os 24 híbridos avaliados, a produtividade média de grãos foi de 2,88 $\mathrm{t} \mathrm{ha}^{-1}$, sendo este valor inferior à produtividade média da região. De acordo com o Instituto Brasileiro de Geografia e Estatística (IBGE, 2014), a produtividade média da produção de sorgo no município de Jataí, GO situa-se em torno de 3,1 t ha ${ }^{-1}$.

Os híbridos mais produtivos foram 1096030, 10102063, 729033 e 1105653, enquanto o híbrido 1099038 foi o menos produtivo, sendo que a produtividade média de grãos variou entre 1,55 a 4,09 $\mathrm{t} \mathrm{ha}^{-1}$.

Tardin et al. (2012), avaliando o rendimento de grãos de 25 híbridos de sorgo granífero em nove regiões brasileiras, obtiveram diferentes produtividades, sendo que apenas um material testado apresentou rendimento superior à média nacional.

Ainda segundo os mesmos autores, o sorgo, na região Centro-Oeste, normalmente é cultivado em época de safrinha tardia, fato este que reflete em uma produtividade média bem abaixo do potencial produtivo dos materiais disponíveis no mercado. De acordo com Santos et al. (2005), nas condições de 
safrinha e safra é possível obter produtividades de $7 \mathrm{t} \mathrm{ha}^{-1}$ e $10 \mathrm{t} \mathrm{ha}^{-1}$, respectivamente.

\section{CONCLUSÕES}

Dos híbridos avaliados o florescimento médio ocorreu em torno de 63 dias, o 1096030 destacou-se por apresentar maior comprimento de panícula, maior altura de planta e maior produção de massa fresca.

Os híbridos 1096030, 10102063, 729033 e 1105653 apresentam os maiores rendimentos de grãos.

\section{REFERÊNCIAS}

ALMEIDA FILHO, J. E.; SOARES, D. C. P; SILVA, E. A. 2010. Avaliação agronômica de 25 híbridos simples de sorgo granífero (Sorghum bicolor) em distintas condições edafoclimáticas. In. CONGRESSO NACIONAL DE MILHO E SORGO, XXVIII., Goiânia. Anais... Sete Lagoas: ABMS, p. 967-973.

AVELINO, P. M.; NEIVA, J. N. M.; ARAUJO, V. L.; ALEXANDRINO, E.; BOMFIM, M. A. D.; RESTLE, J. 2011. Composição bromatológica de silagens de híbridos de sorgo cultivados em diferentes densidades de plantas. Revista Ciência Agronômica, Fortaleza, v. 42, n. 1, p. 208-215.

CONAB - COMPANHIA NACIONAL DE ABASTECIMENTO. 2015.

Acompanhamento da safra brasileira: grãos safra 2014/2015 - décimo primeiro levantamento. Brasília: CONAB. 101p. Disponível em: <http://www.conab.gov.br/OlalaCMS/upl oads/arquivos/15_08_18_10_30_18_bolet im_graos_agosto_2015.pdf> Acesso em: 25 set. 2015.

FAO - FOOD AND AGRICULTURE ORGANIZATION OF THE UNITED NATIONS. 2014. Faostat. Disponível em:

<http://faostat3.fao.org/download/T/TP/E $>$. Acesso em: ago. de 2015.

FERREIRA, D. F. 2011. Sisvar: A computer statistical analysis system. Ciência e Agrotecnologia, Lavras, v.35, n.6, p.1039-1042.

HECKLER, J. C. 2002. Sorgo e girassol no outono-inverno, em sistema plantio direto, no Mato Grosso do Sul, Brasil. Ciência Rural, Santa Maria, v. 32, n. 3, p. 517520.

IBGE - INSTITUTO BRASILEIRO DE GEOGRAFIA E ESTATÍSTICA. 2014. Produção agrícola municipal 2013. Rio de Janeiro: IBGE. 102p. Disponível em: <ftp://ftp.ibge.gov.br/Producao_Agricola/ Producao_Agricola_Municipal_\%5Banua 1\%5D/2013/pam2013.pdf> Acesso em: Mai.de 2015.

PALE, S.; MASON, S. C.; GALUSHA, T. D. 2003. Planting time for early-season pearl millet and grain sorghum in Nebraska. Agronomy Journal, Madison, v. 95, n. 4, p. 1047-1053.

PAZIANI, S. F.; DUARTE, A. P. 2006. Avaliação de cultivares de milho e sorgo para silagem. Pesquisa \& Tecnologia, Campinas, v. 3, n. 2, 2006. 3p.

RODRIGUES FILHO, O.; FRANÇA, A. F. S.; OLIVEIRA, R. P.; OLIVEIRA, E. R.; ROSA, B.; SOARES, T. V.; MELLO, S. Q. S. 2006. Produção e composição bromatológica de quatro híbridos de sorgo forrageiro [Sorghum bicolor (L.) Moench] submetidos a três doses de nitrogênio. Ciência Animal Brasileira, Goiânia, v. 7, n. 1, p. 37-48.

RODRIGUEZ, N. M.; GONÇALVES, L. C.; NOGUEIRA, F. A. S. 1999. Silagem de sorgo de porte baixo com diferentes teores e tanino e de umidade no colmo I-pH e 
teores de matéria seca e de ácidos graxos durante a fermentação. Arquivo Brasileiro de Medicina Veterinária e Zootecnia, Belo Horizonte, v. 51, p.485490.

SANTOS, F. G.; CASELA, C. R.; WAQUIL, J. M. 2005. Melhoramento de sorgo. In: BORÉM, A. Melhoramento de espécies cultivadas. 2 ed. Viçosa: UFV. p.605-658. SANTOS, J. F.; GRANGEIRO, J. I. T. 2013. Desempenho produtivo de cultivares de sorgo forrageiro e granífero na Paraíba. Tecnologia \& Ciência Agropecuária, João Pessoa, v. 7, n. 2, p. 49-55.

SILVA, A. G.; BARROS, A. S.; SILVA, L. H. C. P.; MORAES, E. B.; PIRES, R., TEIXEIRA, I. 2009. R. Avaliação de cultivares de sorgo granífero na safrinha no sudoeste do Estado de Goiás. Pesquisa Agropecuária Tropical, Goiânia, v. 39, n. 2, p. 168-174.

TARDIN, F. D., ALMEIDA FILHO, J. E., DAHEER, R. F.; MENEZES, C. B.; SILVA, K. J.; PAULA, C. M.; XAVIER NETO, J. B.; ALBUQUERQUE, C. J. B.; BASTOS, E. A.; CARDOSO, M. J.; GODINHO, V. P. C.; ANDRADE, F. F.; LOPES, V. S.; SCHAFFERT, R. E. 2012. Desempenho agronômico de híbridos de sorgo granífero cultivados em vários ambientes brasileiros. In. CONGRESSO NACIONAL DE MILHO E SORGO, XXIX., 2012, Águas de Lindóia. Anais... Sete Lagoas: ABMS. p. 967-973.

VÉRAS, R. M. L.; FERREIRA, M. A.; VÉRAS, A. S. C.; CARVALHO, F. F. R.; CAVALCANTI, C. V. A.; SANTOS, G. R. A.; MENDONÇA, S. S.; SOARES, C. A.; SAMPAIO, C. B. 2005. Substituição do milho por farelo de palma forrageira em dietas para ovinos em crescimento: consumo e digestibilidade. Revista Brasileira de Zootecnia, Viçosa, v. 34, n. 1, p. 351-356.

VON PINHO, R. G.; VASCONCELOS, R. C.; BORGES, I. D.; RESENDE, A. V. 2007. Produtividade e qualidade da
Recebido em: 29/09/2015 Aceito para publicação em: 03/11/2016 